\title{
Improving public policy and administration: exploring the potential of design
}

Names and affiliations:

Arwin van Buuren, Professor of Public Administration, Department of Public Administration and Sociology, Erasmus University Rotterdam and Academic Director of the Erasmus Governance Design Studio.

Jenny M Lewis, Professor of Public Policy, School of Social and Political Sciences, University of Melbourne and Director of the Policy Lab.

B. Guy Peters, Maurice Falk Professor of American Government, University of Pittsburgh.

William Voorberg, postdoctoral researcher at the Department of Public Administration and Sociology, Erasmus University Rotterdam and project manager at the Erasmus Governance Design Studio.

Abstract (100 words):

In recent years, design approaches to policymaking have gained popularity amongst policymakers. However, a critical reflection on their added value and on how contemporary 'design-thinking' approaches relates to the classical idea of public administration as a design science, is still lacking. This introductory paper reflects upon the use of design approaches in public administration. We delve into the more traditional ideas of design as launched by Simon and policy design, but also into the present-day design wave, stemming from traditional design sciences. Based upon this we distinguish between three ideal-type approaches of design currently characterizing the discipline: design as optimization, design as exploration and design as co-creation. More rigorous empirical analyses of applications of these approaches is necessary to further develop public administration as a design science. We reflect upon the question how a more designerly way of thinking can help to improve public administration and public policy.

Key words:

public policy, public administration, design, policy design, design science, co-creation

Word count: 7991 


\section{Introduction}

Governments see themselves as increasingly confronted with complex or wicked problems (such as climate change and migration). Characteristic for such issues is that many different stakeholders are involved, with different ambitions, interests and perceptions. A solution for one actor may imply an increase in problems for others (Head, 2008). At the same time citizens' expectations of public services have increased (Bailey \& Lloyd, 2017; Kimbell, 2016; Armstrong, Bailey, Julier \& Kimbell, 2014; Bason, 2017). In this context, design approaches are seen as a promising way to provide smarter and more agile ways to empathize with these actors and their problems, and to find mutually beneficial opportunities and solutions (Armstrong et al., 2014; Bason, 2016; Mintrom \& Luetjens, 2016).

At the same time, thinking about design for public issues is far from new. Some fifty years ago, Herbert Simon called public administration a design science. That implies, in the view of Simon, that this field is different from the natural sciences since it studies the artificial - or human made - instead of the natural and as such, deals with the contingent instead of the necessary - with how things might be instead of with how things are. Design "is concerned with how things ought to be, with devising artefacts to attain goals" (Simon, 1969: 133). In his view, the core of designing is the ability to deal with situations as one encounters them by both diagnosing the problem and devising a way to deal with it. Whether that solution is the design of a material artefact, a treatment plan for a sick patient or a social welfare policy does not really matter. The idea of public administration as a design science has since then been underlined by several scholars in the field (e.g. Shangraw \& Crow, 1989; Frederickson, 2000; Walker, 2011; Meier, 2005).

However, it seems that the current attention for design and design methods, aligns with a different approach to Simon's. Recent applications of design methods involve the use of design or policy labs, design charrettes and other experimental and exploratory approaches. This suggests the rise of a new set of methods and organizations that potentially have impacts on the policymaking processes. That is, more human- or user-centered (instead of problem-centered) approaches, and an openness to inquiry and creativity, are not always part of more traditional understandings of policy design. Design thinking can help develop new options, focusing on outcomes instead of solutions, providing room for experimenting, and recognizing and exercising a new type of distributed (instead of hierarchical) authority (Kimbell, 2016; Christiansen \& Bunt, 2014).

Arriving at this point, two questions emerge. On the one hand, the contemporary use of design methods raise questions about the similarities and differences between these and more traditional conceptualizations of design in public administration and the possible evolution we can witness in thinking about public administration (PA) as a design science. Furthermore, focusing on the potential of design thinking, one could ask to what extent PA as a field can benefit from the application of design methods and principles. Applying design (as the design thinking literature refers to it) to policy-making and service delivery also raises serious questions about the applicability of these design methods which are mostly derived from industrial and product design. Moreover, it raises serious dilemmas when it comes to typical public administration values, such as accountability, legal certainty and predictability (Hillgren et al. 2011, Gasco 2017; Considine et al. 2009).

This special issue addresses these issues. We try to clarify these dilemmas and difficulties, in order to bring the debate on design for policy and public administration to a higher level. Too often, we witness 
a rather uncritical appraisal of design and design thinking without serious attention directed at understanding its limitations and side effects. Moreover, there appears to be a rather deep chasm between the more traditional and more contemporary design approaches in the field, while the opportunities for cross-fertilization are not explored let alone utilized. Until now, systematic empirical attention for the new design approach in PA is lacking. The same holds true for a critical reflection on the question of whether a more designerly way of thinking (Cross, 2011) can help to improve public administration and public policy. We therefore need a better understanding of the different applications of design in the fields of public policy and public administration and their implications, in order to say something substantiated about the potential contribution of the present-day design orientation to public administration.

In this introductory paper we elaborate in sections two and three how the design orientation in the study of public administration and public policy manifested itself over the last decades. In section four, we elaborate what characterizes the current attention for design in public administration and public policy and how we can explain this attention. Subsequently, in section five we argue that we can distinguish three ideal-types of design approaches that are now simultaneously present in public administration and public policy. We examine how these types are similar or different in terms of logic, methods and motives. In section six, we explain how we can explain and understand this proliferation of different design perspectives in public administration and public policy. In section seven, we introduce the contributions of this $\mathrm{SI}$ and assess how they can be considered illustrations of one or more of the ideal-types as identified in section five. In the last section, having a more elaborate understanding of these three ideal-types, generated from the contributions in this paper, we draw some conclusions on the promises of design for public administration and public policy.

\section{Public administration: a design science}

Without doubt, Herbert Simon is the main point of reference when it comes to the idea of PA as a design science. In his seminal work 'The science of the artificial' (1969) he elaborated on this idea. Based upon his idea of bounded rationality, Simon focused on all kinds of systematic decision support systems to enhance the search for optimal design solutions. Other scholars, like Trudi Miller (1984), Lawrence Radine (1987) and Vincent Ostrom (1974) also contributed to the idea of PA as a design science. In his article on the intellectual crisis in American public administration, Ostrom stated: "An appropriate theory of design is necessary both to understand how a system will work and how modifications or changes in a system will affect its performance" (1974: 102).

In line with the approach taken by Simon, others have also argued for further developing the field of PA as a design discipline (Keiser \& Meier 1996). However, their plea mainly ends in an argument for using more sophisticated methods for analyzing data in order to facilitate the step to prescription. This is quite a dominant logic in publications that focus upon PA as a design science. Most of this literature problematizes this issue but does not present convincing illustrations of designs based upon in-depth PA knowledge and it is rarely accomplished with the help of a clear and transparent design methodology.

Another main line of argument has been fueled by studies that apply experimental research logics. Doing experiments (testing interventions) is said to result in usable knowledge which fits into the ambition of the discipline being a design science (Jilke et al. 2017; Walker, 2011). The rise of what is called 'behavioral public administration' has contributed strongly to this line of thinking: testing 
specific interventions with the help of field or survey experiments can help public administration to influence citizens' choice architecture (Grimmelikhuijsen et al. 2017).

The issue of 'public administration as a design science' is thus regularly raised by scholars in the field, but at the moment the most dominant idea is to achieve this by looking for more rigorous experimental research approaches, drawn from the natural sciences. We thus begin from a starting point that the traditional view of PA as a design science is strongly dominated by an informational approach to design (Hermus et al, this issue).

\section{Public policy: a design science}

Simon's concern with design also influenced the study of public policy ("a course of action, adopted or proposed by a government, party, business, or individual" Australian Concise Oxford Dictionary), and one could argue that his interest in design in public administration was driven by a desire to design better public policies. And even before Simon's contributions, Harold Lasswell's discussions of decision-making (1956) and the policy sciences (1951) were directed at finding mechanisms for improving the design of public interventions into the economy and society. As the design approach grew in public policy, however, it was less based on bounded rationality and had more of a technocratic approach.

The assumption of a first wave of analysis (that is, first after Simon and Lasswell) was that the goal of design should be to develop mechanisms or algorithms that would produce clear and usable answers for the policy designer. Beginning with John Dryzek (1983; see also Bobrow and Dryzek, 1987) and then continuing through Linder and Peters (1984; 1991,) this approach was seen to be excessively optimistic about the capacity to produce viable policy designs, given some of the political pitfalls that might arise in designing.

Policy instruments were one of the elements included in the algorithms of the first wave of design. A second wave of thinking about policy design focused almost exclusively on the design and selection of instruments (Howlett, 2010; Howlett and Lejano, 2013). While this literature did develop the analysis of policy instruments far beyond the initial work by Christopher Hood (2007) and others, it still appears to have been quite narrow in focus, especially because it tended to ignore issues such as problem structuring and evaluation in the design process. Although perhaps more attuned to political constraints than some of the earlier literature on policy design, much of the approach based on instruments still assumed a capacity for experts and analysts to develop the correct answers for policy problems and to be able to implement those answers with relative ease. Updated for the digital age (Hood and Margetts 2007) to expand its focus on how government gets information, these contributions provide high-level accounts of design for policy, based on the detectors and effectors that governments use to steer states.

The design orientation is thus strongly manifest in the literature on policy design. In this literature, the central question is how policies (and the way in which they are accomplished) can be designed in such a way that they effectively solve the issues they are meant to act upon. Whenever governments make policy, alone or in conjunction with their partners in the private sector, some form of policy formulation is involved (Jordan and Turnpenny, 2015). That formulation may be relatively unconscious, simply treading the same paths that have been used in the past, as the historical institutionalists would argue. Or the formulation may be a more conscious process of designing policy (Turnbull, 2018). Such a design process will involve developing a policy that is related to the understanding of the policy problem, an explicit set of goals and values, and the strategies for implementing the policy. 
Processes of policy design and formulation have often been performed within government itself, often by the public bureaucracy, and perhaps by legislatures. However, policy design efforts have also involved expertise from outside the public sector, whether from think tanks, universities or private consultants. In contemporary times, designing has been opened even further to include stakeholders from the private sector and citizens.

\section{4. 'Designerly' approaches in public administration and public policy}

It seems nowadays that approaches to design for policy and public administration have turned a corner. Many governments are experimenting with design labs and are applying design methods or design thinking to their primary processes of policy-making, service delivery and decision-making. This new use of 'design' is characterized by a process of creativity and participation. The latter implies that more ideas from different sources are included. This can be labelled as design for policy. In this process, design is considered a way to better understand and structure a policy problem, rather than finding solutions for predefined goals (Hoppe, 2018). While much of the earlier literature sought to eliminate options quickly in order to settle on the apparent best solution, design thinking approaches to policy design have attempted to include a wider variety of actors in the policy process and create a wider range of possible solutions.

This new approach of design finds fertile ground in contemporary governance approaches, in which collaboration is sought with civil society to come up with solutions for contemporary problems, by organizing processes of co-creation and social innovation (Considine and Lewis, 2003; Ansell and Gash, 2007; Hartley et al. 2013). As such, design becomes by definition a process of co-design. Codesign is considered an interesting way to organize such a process (Bovaird and Loeffler, 2012; Farr, 2013). This coincides with a change in the field of industrial design, as designers have sought to evolve design into a framework for solving social problems through actively engaging with those affected (Torjman 2012). Transferred to the public domain, the focus on end-users is present in the New Public Management paradigm, pushing the desires and wishes of end users (as clients asking for value-formoney) to the fore. It is even more apparent in the current collaborative approaches, where end-users are considered to be co-creators or co-producers of public policy and services (Rhodes, 1996; Considine and Lewis, 2003; Torfing et al, 2012), thereby striving for legitimate policy and/or public service, rather than effective policy and services.

These kind of design approaches provide methods to redesign policies, services and goods based upon the perspectives, needs and experiences of the end-users. The underlying assumption is that such an inclusive approach may increase the satisfaction of the end-users and their appreciation of public policy actions. This is in line with new (network) modes of governance that sit in contrast to hierarchical or market driven means of coordinating. While there is a significant difference between tokenistic consultation and genuine end to end user engagement, it is clear that a focus on collaboration and the involvement of users has contributed to the growth of design approaches.

Such a perception of design is thus clearly distinct from the (boundedly) rational and deductive idea of policy design, i.e. design of policy (as described in section three and which sits easily with Simon, and is about devising policies that will address a particular set of goals). In that conception, the design of public policy is considered a set of sequential steps that begins with a problem and results in a solution to that problem. As such, it is based on the ubiquitous policy cycle (first proposed by Laswell in 1956). The set of steps that unfold in between in this model (agenda-setting, policy formulation, decision making, implementation, and evaluation) have been roundly criticised, but still 
provide a useful heuristic framework and a means for structuring what is a vast field (Jann and Wegrich 2007).

One major break that design for policy represents from a 'traditional' policy process (design of policy) is the breadth of the search in identifying problems and solutions. A second break is the focus on empathy, rather than rationality and/or political considerations, in addressing policy problems. A third is the inclusion of all those affected by a particular problem in working towards understanding how to define it in order to address it. A fourth is a focus on the idea of working with provisional ideas (following the logic of abduction), resulting in a search to find ways to approach policy-making as a process of (rapid) prototyping (Kimbell \& Bailey, 2007). These differences with more traditional approaches of policy design, as conceived by those who are seeking value-maximising solutions, even when they recognise the bounded nature of this, bring with them a different set of principles, approaches and methods for arriving at solutions. The design approach begins with empathy rather than a dispassionate rationality as a fundamental principle for policymaking. It applies human-centred design as an overarching approach, which uses creative principles and works on the needs, contexts, behaviours and emotions of those who are affected, to design solutions that serve their needs. As such the design process can be considered as important as what is being designed (output). The techniques they employ include rapid prototyping and trial and error, agility and sprints, and a range of methods that seek to generate 'outside the box' ideas.

The question arises how we can explain the (renewed) attention for design in public administration and public policy. We discern two important arguments given by scholars in the field.

First, many of them stress the fact that design fits well the complexity of many public issues. It is a common notion in the design sciences that traditional scientific research (inductive or deductive) are suitable to "tame" or "determinate" issues, but that wicked issues require methods that enable abduction (intelligent speculation, probability reasoning), trial-and-error and an iterative exploration of the "problem space" and the "solution space" (Dorst \& Cross, 2001; Dorst, 2006, Wylant, 2010). Turnbull (2018) argues in that regard, that for policy makers, policy design offers an orientation that supposes a possibility to consider public policy that can be designed in terms of ends and means. The 'double diamond' created by the Stanford Design School has been replicated (and modified) many times and is now widely used as a basis for all sorts of trail design approaches. At its core is the notion of two motions of opening up (divergence) followed by narrowing down (convergence) - first in relation to the problem and then in relation to the solution. The four-steps of discover, design, develop, and deliver, are close to ubiquitous in design thinking, and have spread rapidly by means of public innovation units and policy labs with a commitment to this new means of tackling problems. These have strong international networks (McGann et al 2018) and a process of transferring ideas between them is apparent in studies of public sector innovation units (Tonurist et al 2017).

Second, the increased attention for design can be attributed to the fact that there is an increased focus on innovation and learning in the public sector. The multiple challenges that have faced governments at all levels over the last few decades, and especially following the last global financial crisis and the introduction of new austerity measures in many nations, have often been seen as requiring innovative approaches. This has moved innovation to center stage in the public sector, taking it well beyond its beginnings as an evolutionary economics concept of 'creative destruction' following Schumpeter (1934), applied only to the development of new products for greater profits. Innovation in a public sector context has caught the attention of governments seeking to address intractable problems with fewer resources, while faced by an increasingly skeptical and demanding populace 
(Lewis et al 2017). The rise of the idea of innovation inside government, rather than government merely supporting innovation by the private sector (Considine et al 2009), and a more recent focus on the innovation capacity of public sector organizations (Lewis et al 2017), can be seen around the world. Governments routinely award public sector innovation prizes in many countries. The European Commission has been prioritizing research grants on public sector innovation (or social innovation) for some years now, which has resulted in comparative research on the topic across its member states. It has also created the Innobarometer to map and rank member states. Others have created innovative city indices and the smart city movement has taken off around the world. In line with these broad trends, there seems to be a growing willingness to explore new methods, tools and approaches and to test them in a rather pragmatic and iterative way. This is accompanied by a call for greater tolerance for making mistakes and learning from them, in the safe space afforded by a pilot, a (living, urban or field) lab environment or a policy experiment.

\section{Coining design approaches in public administration and public policy}

In the current design discourse in the field of public administration and public policy, we can at least discern three different design approaches. The most influential design approach in public administration departs, in line with the work of Simon, arises from a rational design perspective, or design as optimization. These contributions sit easily with a formal design methodology, based upon expertise, objectivity and rationality. In that logic, design is a matter of search and discovery: it is about developing systematic search approaches that help to simplify or even solve complex problems (Alexander, 1982). In the contribution of Hermus et al. (this issue) this is called the informational approach of design, which covers the vast majority of design-oriented studies in the field. These approaches can either be highly expert-driven (without any room for users or stakeholders to influence the design process), or there can also be room for various levels of consultation with stakeholders who provide input or feedback on a scientifically induced design.

Second, the domains of public policy and public service delivery are witnessing a steep rise of interest in pragmatic, 'learning-by-doing' approaches to solve perilous issues (a more 'inspirational' approach of design (see Hermus et al., this issue). These design as exploration approaches involve living labs, design charrettes, policy experiments, prototyping and other innovative ways of finding solutions for contemporary policy problems. As such, design-oriented methodologies are more and more used to formulate public policies or to design public services (Bason, 2016; Mintrom \& Luetjens, 2016). This may involve the design of policies and services, which aims to find solutions to wicked problems in a new and creative way. As the survey of Lewis et al. (this issue) shows, these public sector innovation labs use all kinds of design methods and focus predominantly upon the first phases of the design and policy cycle: problem exploration and idea generation. The paper of Waardenburg et al (this issue) shows an example of such a design approach used as method for a learning and coaching program for public professionals dealing with crime-fighting. Design methods (for example a customer journey or service blueprinting) not only foster creativity, they also enable explicating and assembling (tacit) knowledge and expertise from different sources into testable artefacts.

The third approach conceptualizes design as a matter of co-creation and dialogue, i.e. design as codesign with users and stakeholders. Many design approaches are characterized by a strong focus on co-design, which refers to the inclusion of multiple stakeholders (e.g. citizens, NGO's, public and private professional organizations) in the design process (Blomkamp, 2018). Such a participatory 
conception of design finds it origins in design studies (e.g. (Kolko, 2010a; Norman \& Verganti, 2014; Xenakis \& Arnellos, 2013), thereby focusing on the deliberative and reasoned approach to design. The review of Hermus et al. reveals that especially the more participation-oriented and user-centered design approaches emphasize the value of design as a way to co-create with a wide variety of actors. Design is considered as a way to arrive at social innovation, by inviting the "unusual" actors to the process of policy making. Designing as an activity enables joint learning and reframing. The latter application of design departs from the idea that design is especially suitable in a context of wicked or ill-structured issues - although this is largely untested in practice. The creativity that is allowed by a design approach but also its focus on joint imagination and overcoming frame controversies make design a promising avenue for dealing with social challenges. At the same time, to date the empirical evidence to substantiate this claim remains rather slim.

We thus can distinguish three ideal-type design approaches. One approach begins from a rational strand whereby design can be considered as a method to find the best solution (within limits) for a certain problem (design as optimization). It sits easily with Simon's work on the topic. The second perspective uses design methodology to enhance creativity, learning and experimentation. Third, we distinguish a perspective that focuses upon the idea of design as a matter of co-creation, dialogue and shared sense-making. In this body of literature the notion of co-design is emphasized. Design is a matter of mobilizing all relevant stakeholders in an attempt to jointly create solutions to persistent problems. In the two latter approaches the emphasis is often at least on the process of learning, inspiring and reflection as on the ultimate outcomes in terms of products or artefacts. These three types are not mutually exclusive. Table 1 summarizes them.

\begin{tabular}{|l|l|l|l|}
\hline & $\begin{array}{l}\text { Design as (bounded) } \\
\text { optimisation }\end{array}$ & Design as exploration & Design as co-creation \\
\hline Logic & $\begin{array}{l}\text { Design as translating } \\
\text { knowledge into the best } \\
\text { possible solution }\end{array}$ & $\begin{array}{l}\text { Design as a creative art: } \\
\text { finding novel solutions to } \\
\text { problems }\end{array}$ & $\begin{array}{l}\text { Design as a participatory } \\
\text { endeavour: all affected } \\
\text { actors engage in defining } \\
\text { problems and solutions }\end{array}$ \\
\hline $\begin{array}{l}\text { Methods } \\
\text { used }\end{array}$ & $\begin{array}{l}\text { Tools to translate formal } \\
\text { knowledge into artefacts. }\end{array}$ & $\begin{array}{l}\text { Tools that foster out-of-the- } \\
\text { box thinking and innovation }\end{array}$ & $\begin{array}{l}\text { Tools for dialogue and } \\
\text { interaction }\end{array}$ \\
\hline Motive & $\begin{array}{l}\text { Putting the best available } \\
\text { knowledge into solutions } \\
\text { helps practice to solve its } \\
\text { problems. }\end{array}$ & $\begin{array}{l}\text { Design thinking can enlarge } \\
\text { the solution space, foster } \\
\text { creativity and enhance } \\
\text { imaginative power }\end{array}$ & $\begin{array}{l}\text { Design processes can bring } \\
\text { actors together, foster } \\
\text { learning and build consensus }\end{array}$ \\
\hline $\begin{array}{l}\text { Related } \\
\text { concepts }\end{array}$ & $\begin{array}{l}\text { Evidence-based design, } \\
\text { scientific design, knowledge- } \\
\text { based design, design as } \\
\text { problem-solving }\end{array}$ & $\begin{array}{l}\text { Design-thinking, open } \\
\text { innovation, design as } \\
\text { imagination }\end{array}$ & $\begin{array}{l}\text { Co-design, collaborative } \\
\text { design, participatory design }\end{array}$ \\
\hline
\end{tabular}

Table 1. Three design approaches in Public administration

\section{Illustrating three design approaches - the content of this special issue}

In this special issue, our selection of papers illustrates about each of these approaches what are main issues and questions to be addressed. Hermus, Van Buuren and Bekkers present the results of a 
systematic literature review of design-oriented studies in the field of public administration. Although they found a wide variety of methods and approaches, they also conclude that there is an overrepresentation of more expert-driven and informational design approaches. Moreover, collaboration is often restricted to public officials and to consultation instead of co-creation. Finally, although a more design led way of thinking is increasingly used in practice as a way to come to policies and services, it is (until yet) not used by scholars in the field as a method for investigation or doing research. They put a provocative question on the agenda of our discipline, which is about how to connect design and design thinking to our way of doing research in order to intertwine scientific and societal validation of our knowledge and to increase our impact as a field.

The contribution of Howlett clearly approach policy design as a way of optimisation. Howlett examines how policy design entails a variety of approaches to formulate policy (see also Howlett, 2018). He advocates for a distinction with 'design thinking', which is a form of reasoning backwards from the value to be created by a policy endeavour. He emphasizes the merits of a design approach to policy compared to non-analytical ways of policy-making. In his view, design involves knowledge of the basic building blocks or materials with which actors must work in constructing an artifact such as a product or policy. It also means the elaboration of a set of principles regarding how these materials should be combined in that construction, and the requisites for making such combinations. Moreover, designing effective policies presuppose a clear understanding of the processes by which a policy alternative becomes translated into reality and the barriers that exist between concept and realization. Olejnizak et al. discuss how policy labs are effective vehicles to find solutions to contemporary policy problems. They conclude, among other things, that policy labs can strengthen the quality of policy evaluations, since they offer a safe place, that encourages involvement of other stakeholders. Thereby improving their effectiveness. For instance, they argue that policy labs are well equipped to determine the feasibility and scalability of policy programs, due to a more flexible timeframe than regular policy implementation. This allows for trial and error and ex-ante pilot studies.

Debating design as exploration, Peters illustrates how the institutional context as a delimiter of design space and whose paper underlines the importance of institutional design as a condition for effective policy design (see also Heikkula and Andersson, 2018). In doing so, his contribution attributes to a more elaborate understanding of how the institutional context is conditional to allow design thinking to thrive. Consequently, one may argue that public policy is in need for methodological innovation, beyond existing methods of action research and design experiments. This is the focal point in the contribution of Romme and Meijer building forth on the work of Simon. They examine how the Design Science perspective enables PPA scholars to embrace a broad array of both research outputs and validation. In doing so, different traditions and notions of theory testing is represented in one approach. Lewis et al. argue that Public Sector Innovation (PSI) labs are proliferations of 'design-forpolicy', that is developing policy proposals and reforms. These labs allow various stakeholders to collectively experiment on innovations. This can be concluded from their survey results, that shows how the majority of these labs use human-centered methods, rather than for instance evidence-based methods. However, they point out how co-design may imply something different than including creativity in the policy process. Thereby, demarcating the difference between the second and third perspective.

Design as co-creation, is addressed by two papers. For starters, Waardenburg et al. show how design in a collaborative context may take shape. They argue that in order to create a problem-solving space, continuous feedback; a facilitative process (such as the inclusion of both future and current collaborators); and an accountability structure are prime conditions for co-design. Bryson et al., building forth on their three-dimensional view of power, explore how design explores the basic 
settings of public action (i.e. forums, arenas and courts). They examine in their paper how these settings need to be (re)designed in order to facilitate collaborative governance.

It is important to analyse critically new design approaches and their effectiveness to come up with and deliver innovative policy interventions (design of services, interventions, tools, et cetera). The rapid evolution of all kinds of labs, studios, ateliers, and so on and the uncritical application of all kinds of design-based or inspired methods and tools deserves to be assessed more objectively, in order to find out whether and under which conditions such approaches really add to traditional ways of designing policies. While there is a rapidly growing body of cases that suggest that these approaches can work well on the 'front end' of a range of problems, helping to understand what the problem actually is, it is much less certain that they can work on improving policy decision making and changing policy systems. Related to that, it seems that these approaches are useful for service design but the evidence on their utility for policy design is much less clear (see: McGann et al 2018a; 2018b; Lewis et al this issue). Hence, several papers of this special issue also address the potential, but also the shortcomings of design-oriented approaches in public policy (Lewis et al and Olejniczak et al).

\section{The promises of design-oriented thinking for public administration and public policy}

From the various articles in this issue, we can conclude that the use of design approaches in public administration is potentially very promising and can help to revitalize the idea of public administration as a design science, which can enhance its societal relevance and impact. It fits well into the current emphasis that many governments are placing on qualities like participation, learning, creativity and public value.

The current emphasis on evidence-based or evidence-informed policies fit nicely in the idea of design as optimization. Policy-analytical and other forms of knowledge are used (in a systematic and rigorous way) to contribute to more rationalized and analytical ways of problem-solving (as it is approached in the tradition of Laswell, cf. Turnbull, 2018). Unlocking existing knowledge and combining different sources of knowledge can help policy-makers tremendously to enhance the effectiveness of governmental steering attempts. The same holds true for simulations, scenario exercises, data visualisations and the like. These methods are rapidly entering the world of public policy and management, often enthusiastically appraised by innovation labs and other agencies (Williamson, 2015).

Design as exploration allows policy makers to opt for a more hypothetical way of working: possible and plausible solutions can be tested and refined. In doing so, design offers an approach to both creatively and systematically explore what the best solution is to the policy problem. In this approach, the benefit of design lies predominantly in broadening the scope of solutions that are taken into account and the room for experimentation (Dorst, 2011), which is usually not characteristic of governmental efforts. Therefore, in a context which is generally dominated by accountability structures, a design approach offers the liberty to imagine alternative solutions. As Peters shows in his contribution to this issue, that might create tension with existing institutions and even may ask for heavy reconsideration of these institutions. However, due to the out-of-the-box character of this design approach, it offers tools to develop in collaboration with other stakeholders, interventions and products that potentially may work.

This is where the benefits of the second approach also touches upon the benefits of the third approach - design as co-creation. By including multiple stakeholders (e.g. stemming from both business and civil society alike) into the development of policy/public service, the design orientation allows for creativity and imagination in public policy, which may improve its quality. Moreover, due to its inclusive character, design as a form of co-creation can facilitate a stronger user-orientation in 
policy-making and service-provision by including citizens and end users as co designers, which also can add to its perceived legitimacy.

\section{Public administration and public policy as a design science - the next steps}

Doing design as exploration or co-creation is from an academic point of view a promising route. If done systematically we can think of a policy design as a hypothesis and about policy-making as a kind of prototyping (Kimbell \& Bailey, 2017). Clear assumptions about the nature of the problem and the possibilities of intervention can be tested through implementation. Evidence-based policymaking, as an ancillary to design ab initio, provides sources of previously tested modes of intervention. That said, some skepticism is also required, given the complexity of the world into which public policies are introduced. There is a plethora of possible alternative causes for policy success and failure, so that any experiment that is conducted with a design approach will still be contingent upon context (Pollitt, 2013).

From a public policy and public administration perspective, the growing popularity of design thinking is important for the development of the field. Following Herbert Simon, the public administration discipline has been repeatedly labelled as a design science, but it has often failed to live up to that promise. Both in policy studies and in public management studies, we can find many examples of design thinking research (Kellie et al. 2012; Iglesias, 2014), but this has generally not represented the mainstream of the field. The question about the essential characteristics and building blocks of a design thinking approach for public administration and public policy is still unanswered. There are complementarities and tensions between policymaking and design thinking (see both Lewis et al, Peters, and Howlett, all in this issue). The important question here is to what extent the rise of current design thinking approaches in the field can contribute to the potency of public administration and public policy as scientific disciplines that combine both analytical rigor and societal relevance.

Doing design-based research is, for policy scientists, maybe not directly part of their comfort zone. It asks them to do their research as a designer. By creating, testing and refining designs, they can get a deeper understanding of policy problems, the context in which they are located, the needs that actors identify, and the impact of certain solutions. The latter asks also for more advanced experimental methods and ways to systematically analyse how solutions work out in practice, and which dynamics they cause. It also asks for a more systematic approach to applying design elements in more classical ways of doing research. This is a challenging endeavour because of the focus of design on abductive reasoning instead of induction and deduction, and the role it gives to intuition, creativity and imagination. Bringing these worlds together and giving both of them the place they deserve, requires methodological innovation beyond existing methods of action research and design experiments. There seems to be a long way to go before a more 'design-inspired' way of doing research in public administration will be settled as a normal way of doing rigorous research in a societally relevant way. However the various contributions in this issue show that it is a promising next step in thinking about public administration as a design science. This also presupposes that there are opportunities to find new combinations of the traditional ways of doing design (the informational approach, in the tradition of Simon) along with ways of doing design from a more inspirational stance.

This special issue also makes clear that there are many unanswered questions about the peculiarities of design remaining. For example, when it comes to the politics of design: who are the actors that benefit from design and who are the actors that are disadvantaged? And how does that help or obstruct the design of legitimate policy and/or public services? To what extent is design a way to come 
to collaborative decision-making or is it used as a way to depoliticize sensitive issues in a way that ignores the values at stake? Also, there is the question of in what type of context the application of a design approach is helpful and in what contexts it is less effective? To what extent are successful (in a particular context) methods of design transferable to other contexts and policy levels? Moreover, how can we more rigorously assess design efforts and their effectiveness relative to other approaches of problem solving?

Many governments are experimenting with design thinking approaches and are developing design labs or centers to introduce design methods and tools within their own context. One of the most surprising observations with regard to this trend has to do with the fact that only little attention is paid to the peculiarities of this context. Within a public context other conditions play a role compared to a private, market-oriented context. Politics but also legal principles, the need for accountability and public bureaucracies not only set specific conditions on processes of co-creation and co-design but also limit the room for creativity. This also makes a more experimental approach to policy-making and service formulation difficult. In other words, the design space in a public context has its own, unique boundaries which are often more restrictive compared to a private context in which design thinking is commonly used to develop products and services. Reflecting upon what a public context implies for applying design-oriented methods and how these methods can become allied with the more analytical design tradition in the field are important challenges to be tackled in the next coming years.

Funding details:

No external funding was received for drafting this manuscript

Conflict of interest:

The Author(s) declare(s) that there is no conflict of interest

\section{References}

Alexander, S., \& Orbach, R. (1982). Density of states on fractals: Journal de Physique Lettres, 43(17), 625-631.

Ansell, C. and Gash, C. 2007. 'Collaborative governance in theory and practice.' Journal of Public administration Research and Theory 18(4): 543-571.

Armstrong, L., Bailey, J., Julier, G., \& Kimbell, L. (2014). Social design futures: HEl research and the AHRC.

Bason, C. (2016). Design for policy. Oxon: Routledge.

Bason, C. (2017). Leading public design: Discovering human-centred governance. Policy Press.

Bailey, J., \& Lloyd, P. (2017). The introduction of design to policymaking: Policy Lab and the UK government. Annual Review of Policy Design, 5(1), 1-14.

Blomkamp, E. 2018. 'The Promise of Co-Design for Public Policy'. Australian Journal of Public administration, n/a-n/a. https://doi.org/10.1111/1467-8500.12310.

Bobrow, D. And J. S. Dryzek (1987) Policy Analysis by Design (Pittsburgh: University of Pittsburgh Press).

Bovaird, T. (2007). Beyond engagements and participation: user and community coproduction of public services. Public administration Review, 67(5), 846-860

Bovaird, T., \& Loeffler, E. (2012). From engagement to co-production: The contribution of users and communities to outcomes and public value. Voluntas: International Journal of Voluntary and Nonprofit Organizations, 23(4), 1119-1138.

Bryson, J. M., Crosby, B. C., \& Bloomberg, L. (2014). Public value governance: Moving beyond traditional public administration and the new public management. Public administration Review, 74(4), 445-456. 
Bryson, J. M., Quick, K. S., Slotterback, C. S., \& Crosby, B. C. (2013). Designing public participation processes. Public administration review, 73(1), 23-34.

Christiansen, J., \& Bunt, L. (2014). Innovating Public Policy: Allowing for social complexity and uncertainty in the design of public outcomes. Design for policy, 41-56.

Considine, M, Lewis, JM and Alexander, D. 2009. Networks, innovation and public policy: Politicians, bureaucrats and the pathways to change inside government. Basingstoke: Palgrave Macmillan.

Considine, M., \& Lewis, J. M. (2003). Bureaucracy, network, or enterprise? Comparing models of governance in Australia, Britain, the Netherlands, and New Zealand. Public Administration Review, 63(2), 131-140.

Cross, N. (2011). Design thinking: Understanding how designers think and work. Berg.

Dorst, K. \& Cross, N. (2001). Creativity in the design process: co-evolution of problemsolution. Design Studies, 22(5), 425-437.

Dorst, K. (2006). Design Problems and design paradoxes. Design Issues, 22(3), 4-17.

Dorst, K. 2011. 'The core of 'design thinking' and its application'. Design Studies 32: 521-532. Hood, C. 1983. The tools of government. Macmillan.

Dryzek, J. S. (1983). Don't toss coins in garbage cans: A prologue to policy design. Journal of Public Policy, 3(4), 345-367.

Farr, M. (2013). 30. Citizens and the co-creation of public service innovations. Handbook of Innovation in Public Services, 445.

Fung, A. (2006). Varieties of participation in complex governance. Public administration review, 66, 66-75.

Frederickson, H. G. (2000). Can bureaucracy be beautiful? Public administration Review, 60(1), 47-53.

Gascó, M. (2017). Living labs: Implementing open innovation in the public sector. Government Information Quarterly, 34(1), 90-98.

Grimmelikhuijsen, S., Jilke, S., Olsen, A. L., \& Tummers, L. (2017). Behavioral public administration: Combining insights from public administration and psychology. Public administration Review, 77(1), 45-56.

Hartley, J., Sørensen, E., \& Torfing, J. (2013). Collaborative innovation: A viable alternative to market competition and organizational entrepreneurship. Public Administration Review, 73(6), 821830.

Head, B. W. (2008). Wicked problems in public policy. Public policy, 3(2), 101.

Heikkula, T and K. Andersson (2018) Policy Design and the Added Value of the Institutional Analysis Development Framework, Policy \& Politics 46, 309-24.

Hillgren, P. A., Seravalli, A., \& Emilson, A. (2011). Prototyping and infrastructuring in design for social innovation. CoDesign, 7(3-4), 169-183.Hood, C. 1984. The tools of government. London: MacMillan.

Hood, C. (2007). Intellectual obsolescence and intellectual makeovers: Reflections on the tools of government after two decades. Governance, 20(1), 127-144.

Hood,C. and Margetts, H.Z. 2007. The tools of government in the digital age, $2^{\text {nd }}$ ed. London: Palgrave Macmillan.

Hoppe, R. (2018). Heuristics for practitioners of policy design: Rules-of-thumb for structuring unstructured problems. Public policy and administration, 33(4), 384-408.

Howlett, M. (2010) Designing Public Policy: Principles and Instruments (London: Routledge).

Howlett, M. and R. P. Lejano (2013) Tales from the Crypt: The Rise and Fall (and Rebirth?) Of Policy Design, Administration \& Society 45

Howlett, M. (2018) Matching Policy Tools and Their Targets: Beyond Nudges and Utility Maximization in Policy design, Policy \& Politics 46, 101-24.

Iglesias Alonso, A. (2014). The shaping of local self-government and economic development through city strategic planning: A case study. Lex Localis, 12(3), 373-391. 
Jann, W., and Wengrich, K. 2007. 'Theories of the policy cycle'. In: F. Fischer, G.J. Miller and M.S. Sidney (eds) Handbook of public policy analysis. Theory, politics and methods. New York: CRC Press, 43-62. Jilke, S., Van de Walle, S., \& Kim, S. (2016). Generating usable knowledge through an experimental approach to public administration. Public administration Review, 76(1), 69-72.

Jordan, A. J. and J. R. Turnpenny (2015) The Tools of Policy Formulation (Cheltenham: Edward Elgar). Kellie, J., Milsom, B., \& Henderson, E. (2012). Leadership through action learning: a bottomup approach to 'best practice' in 'infection prevention and control' in a UK NHS trust. Public Money \& Management, 32(4), 289-296. https://doi.org/10.1080/09540962.2012.691308

Keiser, L. R., \& Meier, K. J. (1996). Policy design, bureaucratic incentives, and public management: The case of child support enforcement. Journal of Public Administration Research and Theory, 6(3), 337-364.

Kimbell, L. (2016). Design in the Time of Policy Problems. Proceedings of DRS 2016, Design Research Society 50th Anniversary Conference., 1-14. https://doi.org/10.21606/drs.2016.498

Kimbell, L., \& Bailey, J. (2017). Prototyping and the new spirit of policymaking. CoDesign, 13(3), 214-226.

Kooiman, J. (ed) 1993. Modern governance: New government-society interactions. London: Sage.

Kolko, J. (2010). Abductive thinking and sensemaking: The drivers of design synthesis. Design Issues, 26(1), 15-28.

Lasswell, H. D. (1951) The Policy Orientation, in Lasswell and D. Lerner, eds., The Policy Sciences: Recent Developments in Theory and Method (Stanford, CA: Stanford University Press).

Lasswell, H. D. (1956) The Decision Process: Seven Categories of Functional Analysis (College Park, MD: Bureau of Government Research, University of Maryland).

Lewis, JM, Ricard, LM, Klijn, EHK and Ysa, T. 2017. Innovation in city governments: Structures, networks, and leadership. London: Routledge.

Linder,S. H. And B. G. Peters (1984) From Social Theory to Policy Design, Journal of Public Policy 4, 237-59.

Linder, S. H. And B. G. Peters (1991) The Logic of Public Policy Design: Linking Policy Actors and Plausible Instruments, Knowledge and Policy 4, 121-51.

McGann, M., Lewis, J. M., \& Blomkamp, E. (2018a). Mapping public sector innovation units in Australia and New Zealand: 2018 Survey Report.

McGann, M., Blomkamp, E., \& Lewis, J. M. (2018b). The rise of public sector innovation labs: experiments in design thinking for policy. Policy Sciences, 1-19.

Meier, K. J. (2005). Public administration and the myth of positivism: The antichrist's view. Administrative Theory \& Praxis, 27(4), 650-668.

Keiser, L. R., \& Meier, K. J. (1996). Policy design, bureaucratic incentives, and public management: The case of child support enforcement. Journal of Public administration Research and Theory, 6(3), 337-364.

Miller, T. C. (1984). Public sector performance: A conceptual turning point. Baltimore, Johns Hopkins University Press.

Mintrom, M., \& Luetjens, J. (2016). Design thinking in policymaking processes: Opportunities and challenges. Australian Journal of Public administration, 75(3), 391-402.

Norman, D. A., \& Verganti, R. (2014). Incremental and radical innovation: Design research vs. technology and meaning change. Design Issues, 30(1), 78-96.

Osborne, S. (2006) The New Public Governance? Public Management Review, 8(3), 377-387

Ostrom, V. (1974). The Intellectual Crisis in American Public administration, University of Alabama Press. E;gar).

Pollitt, C. (2013) Context in Public Policy and Management: The Missing Link? (Cheltenham: Edward

Radine, L. B. (1987). Organization theory in administrative law: A proposal for a design science. The American Sociologist, 18(3), 278-283. 
Rhodes, R. A. W. (1996). The new governance: Governing without government. Political Studies, 44(4), 652-667.

Rhodes, R.A.W. 1997. Understanding governance: policy networks, governance, reflexivity, and accountability. Buckingham: Open University Press.

Schumpeter, J. A. (1934). Change and the Entrepreneur. Essays of JA Schumpeter.

Simon, H. (1969). The sciences of the artificial. Cambridge: The MIT Press.

Shangraw, R.F. \& Crow, M.M. (1989). Public administration as a design science. International Journal of Public administration, 21(6-8), 153-160.

Tõnurist, P., Kattel, R., \& Lember, V. (2017). Innovation labs in the public sector: what they are and what they do?. Public Management Review, 19(10), 1455-1479.

Torfing, J., Peters, B.G., Pierre, J. and Sorenson, E. 2012. Interactive governance: Advancing the paradigm. Oxford: Oxford University Press.

Torjman, L. 2012. Labs: Designing the future. Ontario: MaRS Discovery District. Tõnurist et al 2017

Turnbull, N. (2018). Policy design: Its enduring appeal in a complex world and how to think it differently. Public Policy and Administration, 33(4), 357-364

Walker, R. M. (2011). Globalized public management: an interdisciplinary design science?. Journal of Public administration Research and Theory, 21(suppl_1), i53-i59.

Williamson, B. (2015). Governing methods: policy innovation labs, design and data science in the digital governance of education. Journal of Educational Administration and History, 47(3), 251271.

Wylant, B. (2010). Design thinking and the question of modernity. The Design Journal, 13(2), 217-231.

Xenakis, I., \& Arnellos, A. (2013). The relation between interaction aesthetics and affordances. Design Studies, 34(1), 57-73 


\section{University Library}

\section{- M M I N E R VA A gateway to Melbourne's research publications}

Minerva Access is the Institutional Repository of The University of Melbourne

Author/s:

van Buuren, A;Lewis, JM;Peters, BG;Voorberg, W

Title:

Improving public policy and administration: exploring the potential of design

Date:

2020-01-01

Citation:

van Buuren, A., Lewis, J. M., Peters, B. G. \& Voorberg, W. (2020). Improving public policy and administration: exploring the potential of design. Policy and Politics: an international journal, 48 (1), pp.3-19. https://doi.org/10.1332/030557319X15579230420063.

Persistent Link:

http://hdl.handle.net/11343/267895 